OPEN ACCESS

Edited by:

Jinming Zhang,

Chengdu University of Traditional

Chinese Medicine, China

Reviewed by:

Naresh Kumar Rajendran,

University of Rochester, United States

Mariana Tasso,

Consejo Nacional de Investigaciones

Cientificas y Técnicas (CONICET),

Argentina

*Correspondence:

Gang Zhao

gzhao@jlu.edu.cn

Hongquan Yu

yhq@jlu.edu.cn

Specialty section:

This article was submitted to

Pharmacology of Anti-Cancer Drugs,

a section of the journal

Frontiers in Oncology

Received: 04 July 2021 Accepted: 12 January 2022

Published: 28 January 2022

Citation:

Wang B, Guo $\mathrm{H}, \mathrm{Xu} H$

Chen $Y$, Zhao $G$ and $Y u H$ (2022)

The Role of Graphene Oxide

Nanocarriers in Treating Gliomas.

Front. Oncol. 12:736177.

doi: 10.3389/fonc.2022.736177

\section{The Role of Graphene Oxide Nanocarriers in Treating Gliomas}

\author{
Bin Wang ${ }^{1}$, Hanfei Guo ${ }^{2}$, Haiyang $X u^{1}$, Yong Chen ${ }^{1}$, Gang Zhao ${ }^{1 *}$ and Hongquan $\mathrm{Yu}^{1 *}$ \\ ${ }^{1}$ Department of Neurosurgery, The First Hospital of Jilin University, Changchun, China, ${ }^{2}$ Cancer Center, The First Hospital of \\ Jilin University, Changchun, China
}

Gliomas are the most common primary malignant tumors of the central nervous system, and their conventional treatment involves maximal safe surgical resection combined with radiotherapy and temozolomide chemotherapy; however, this treatment does not meet the requirements of patients in terms of survival and quality of life. Graphene oxide (GO) has excellent physical and chemical properties and plays an important role in the treatment of gliomas mainly through four applications, viz. direct killing, drug delivery, immunotherapy, and phototherapy. This article reviews research on GO nanocarriers in the treatment of gliomas in recent years and also highlights new ideas for the treatment of these tumors.

Keywords: antitumor, cell cycle, graphene oxide, immunotherapy, invasion, metabolism, migration, phototherapy

\section{INTRODUCTION}

Glioma, originating from neuroectodermal cells, is the most common primary malignant tumor of the central nervous system and is aggressive and lethal. Gliomas account for $75 \%$ of intracranial primary malignant tumors and have a high morbidity and mortality $(1,2)$. Glioblastoma multiforme (GBM) is the most common malignant type, accounting for approximately $57 \%$ of all gliomas (3). At present, the standard treatment for GBM is simultaneous maximal safety surgical resection and chemoradiotherapy with subsequent adjuvant chemotherapy for 6 months (4). Owing to the invasive and temozolomide-resistant nature of GBM, the 1-year survival rate of patients with the disease is approximately $41.4 \%$ whereas the 5 -year survival rate is less than $5 \%$ (5). In recent years, much progress has been made in the diagnosis and treatment of gliomas $(6,7)$. The proposal of molecular pathology allows for a more precise diagnosis, which will enable more effective therapeutic approaches (8). The optimization of traditional therapy includes easing the intraoperative delineation and improving spatial and time radio exposure $(9,10)$. Tumor treating fields (TTF) is a newly approved therapeutic approach in high-grade gliomas patients, which is both effective and safe (11). In addition, new therapies such as molecular targeting and immunotherapy have also accumulated more and more experience, but few achievements can change clinical practice protocols or outcomes (12-14). Nanocarriers are pharmaceutically-relevant colloidal systems with sizes in the range of 1-1000 $\mathrm{nm}$. These colloidal systems are capable of treating tumors through direct action or their ability to as drug delivery systems $(15,16)$. The applicability of these nanocarriers in tumor targeting and treatment is accomplished through the following: 1) loading anti-tumor drugs through their ability to act as drug delivery systems, 2) functional modification of the drug-loaded nanoparticles by adding targeting ligands, and 3) using specific physics, chemistry, or biological methods to release the drug in the appropriate amount to exert the 
desired therapeutic effect $(17,18)$. Graphene oxide (GO) nanocarriers have the characteristics of easy modification and good dispersibility and are thus postulated to become a new nanocarrier-based therapeutic option for the management of gliomas. Consequently, research on GO and GO nanocarriers has gradually become a hot topic in recent years (19).

\section{OVERVIEW OF GRAPHENE OXIDE NANOCARRIERS}

\subsection{Graphene Oxide}

Graphene is a 2-dimensional sheet of $\mathrm{sp}^{2}$-hybridized carbon with a honeycomb-like structure (20). Graphene has a relatively complete structure, high stability, and weak interaction with other media, which is not conducive to its use as a drug carrier. $\mathrm{GO}$ and reduced $\mathrm{GO}$ ( $\mathrm{rGO}$ ) are derivatives of graphene. The surfaces of GO and rGO contain a large number of oxygencontaining functional groups such as carboxyl, epoxy, and hydroxyl groups, which can be chemically modified as active sites (21). The existence of a large number of oxygen-containing groups leads to good water solubility and dispersibility of GO and $\mathrm{rGO}$ (22). The skeleton of GO and rGO is an aromatic ring with a large specific surface area and abundant functional groups, which can increase drug loading via $\pi-\pi$ interactions and bind biological macromolecules, such as proteins, nucleotide acid fragments, and aptamers to facilitate functional modification and target recognition $(22,23)$ (Table 1).

\subsection{Graphene Oxide Nanocarriers}

The tumor cells are growing disorderly and dense, so conventional drug delivery systems work only on the surface of the tumor, making it difficult to penetrate deep into the tumor tissue (44). Molecules and nanomaterials with sizes ranging between 10 and $100 \mathrm{~nm}$ can be retained in tumors because of the abnormal blood vessels and the defective lymphatic circulation in tumor tissues. This is known as the enhanced permeability and retention effect (EPR) (45-47). EPR provides an option to achieve spontaneous accumulation of GO for the passive delivery of anti-tumor drugs to tumors. However, EPR provides less than a 2 -fold concentration increase in tumor tissues compared with non-target tissues and organs, and sometimes the efficiency of EPR is too low to reach the drug concentrations sufficient for curing cancer (48). There is difficulty in translating the EPR effect from bench to bedside because of intra- and inter-tumoral heterogeneity, heterogeneity in nanoparticle accumulation in the different tumors, and EPR effects differences between rodent tumors and human tumors (49-52). The GO nanocarrier system has more advantages than the traditional anti-tumor drug delivery system, like liposomes. These include (1) good blood compatibility and optimal dispersibility in the liquid environment of the human body (53); (2) large specific surface area facilitating multi-functional modification by biomolecules and small molecules, such as proteins and single-stranded DNA bases (54); (3) single atomic layer of thickness, and an ultra-high drug loading capacity compared with other nanomaterials (55); (4) sustained release and prolonged drug half-life (56); (5) relatively good biological safety and acceptable toxicity (57-61). Various modification methods have been employed to improve the solubility, stability, and cytotoxicity of GO, while there is still a need to further evaluate the biocompatibility and toxicity of GO nanocarriers into the human body $(57,62)$.

\subsection{Functional Modification of Graphene Oxide Nanocarriers}

Graphene is too stable to react with other materials, which limits its application as a drug nanocarrier; however, GO can easily be functionally modified $(63,64)$. Functional modification of the structure and properties of GO is an effective way to improve the utilization of graphene carriers. At present, functional modification methods for GO are mainly divided into two

TABLE 1 | A brief summary of functional modifications of GO.

\begin{tabular}{|c|c|c|c|}
\hline Graphene composite & Modification material & Observations & Ref. \\
\hline GO & Arginine-Glycine-Aspartate (RGD) & Improving tumor-targeting efficiency & $(24)$ \\
\hline $\mathrm{GO}$ & Polyethylene glycol (PEG) & Improving biocompatibility and drug delivery capacity of GO & (25) \\
\hline GO & Transferrin (Tf) & Improving tumor-targeting efficiency & (26) \\
\hline GO & Monoclonal antibody (mAb) & Improving tumor-targeting efficiency & $(27)$ \\
\hline GO & Carboxymethyl chitosan (CMC) & Improving biocompatibility and drug delivery capacity of GO & $(28)$ \\
\hline GO & Folic acid (FA) & Improving tumor-targeting efficiency & $(29,30)$ \\
\hline GO & Lactosylated chitosan oligosaccharide (LCO) & Improving tumor-targeting efficiency and anti-tumor genes delivery capacity of GO & (31) \\
\hline GO & Polyethylenimine (PEl) & Improving biocompatibility and drug delivery capacity of GO & (32) \\
\hline GO & $\beta$-Cyclodextrin ( $\beta$-CD) & Improving photothermal efficiency & (33) \\
\hline GO & Iron oxide nanoparticle (IONP) & Improving photothermal efficiency and MRI sensitivity & (34) \\
\hline GO & Chlorotoxin (CTX) & Improving drug delivery capacity of GO & (35) \\
\hline GO & Chitosan (CS) & Improving biocompatibility and drug delivery capacity of GO & (36) \\
\hline GO & Poly N-vinyl caprolactam (PVCL) & Improving biocompatibility and drug delivery capacity of GO & (37) \\
\hline GO & Hyaluronic acid $(\mathrm{HA})$ & Improving tumor-targeting efficiency and drug delivery capacity of GO & $(38)$ \\
\hline GO & Pluronic F127 (PF127) & Improving biocompatibility of GO & $(39,40)$ \\
\hline GO & Glycyrrhetinic acid (GA) & Improving tumor-targeting efficiency & $(41)$ \\
\hline GO & Polyetheramine (PEA) & Improving biocompatibility and drug delivery capacity of GO & $(42)$ \\
\hline GO & Poly (acrylic acid) (PAA) & Improving biocompatibility of GO & $(43)$ \\
\hline
\end{tabular}


types: covalent and non-covalent modifications. Covalent modification refers to the use of chemical reactions to modify the oxygen-containing functional groups on the surface of GO. The application of non-covalent bond modification is ingenious. It uses $\pi-\pi$ conjugation, ionic bonds, and hydrogen bonds to modify GO. Functional modification can provide new properties to GO and thus enhance the dissolution of GO in polar solvents to improve its dispersibility (65).

\subsubsection{Covalent Modification of Graphene Oxide Nanocarriers}

The surface of GO contains a large number of active oxygen groups, such as hydroxyl, carboxyl, and carbonyl groups, which can chemically react with other groups through covalent bonds to optimize its performance by forming interactions such as ester and amide bonds. Marcelo et al. used D-mannose to covalently modify GO (man-GO) using mannosylated ethylenediamine, which was found to improve the RBC toxicity and protein corona formation of GO (66). Covalent modification of GO is important in therapeutic pathways. Ouyang et al. covalently modified GO with arginine-glycine-aspartic acid (RGD) and silicon phthalocyanine $(\mathrm{SiPc})$, which is a fluorescence imaging-guided photothermal and photodynamic therapy for cancer (67). Chen et al. further bound GO to anti-HER2 antibodies loaded with dual-drug DOX and 9-aminoacridine, which increased cytotoxicity against cancer cells (27). Both RGD and antiHER2 antibodies are one of the motifs helping improve active tumor-targeting properties. FA also acts as a molecular recognition motif for folate-receptor-positive cancer cells (68). Zhuang et al. covalently linked pGO-FA to hydrophobic paclitaxel (PTX) to overcome its water-insoluble, which exhibited a higher efficiency in killing A2780 cells (69). Xu et al. covalently modified GO with PEG, forming a high potential drug delivery system in cancer therapy. PTX was linked to GO-PEG, exhibiting great water solubility and cancer-killing efficiency $(70,71)$. More et al. covalently linked iron oxide nanoparticles (IONPs) with GO forming GOIOI, which showed great potential in cancer metastasis (72). The modification of the GO surface via a covalent route is strong and not susceptible to the inconsistent external environment, which makes the GO nanocarriers stable with biological systems in vitro or in vivo.

\subsubsection{Non-Covalent Modification of Graphene Oxide Nanocarriers}

The surface of GO has many charges, which can be functionally modified by DNA, some small molecule drugs, or small molecules through non-covalent bonds, such as $\pi-\pi$ conjugation, ionic bonds, and hydrogen bonds, making GO an ideal nanocarrier for drug delivery. Pan et al. combined 5-FU with Tau-GO through a non-covalent bonding mechanism to form 5-FU-Tau-GO, which was reported to continuously release 5 -FU in the acidic environment of the tumor, thus prolonging the duration of action of 5-FU more effectively than 5-FU alone (73). Wang et al. non-covalently modified GO with PF127 and doxorubicin (DOX), which exhibited a high loading capacity and better biocompatibility (39). Li et al. established non-covalent interaction between trastuzumab (TRA) and GO, enhancing HER2-binding activity to kill osteosarcoma (74). Lin et al. found that noncovalently combined GO with hypocrellin A (HA) can be excited by light irradiation and cause tumor cell death in vitro (75). Li et al. developed an anticancer drug delivery system by the decoration of GOIOI with doxorubicin and non-covalent PEGylation, which combined chemotherapy with phototherapy (34). Wang et al. noncovalently loaded DOX onto GO-chlorotoxin (CTX), and DOX showed in $\mathrm{pH}$-dependent sustained-release manner (35). However, noncovalently modified GO may load fewer aromatic drugs than covalently modified GO.

\subsection{Biocompatibility of Graphene Oxide Nanocarriers}

The potential toxic effect of GO on living cells and organs limits its use in cancer therapy. Clinical use of GO requires extensive studies on its potential short- and long-term toxicity in vivo and in vitro, mainly through cell experiments and animal models to assess its biosafety. GO is much less toxic than graphene since the surface of GO is rich in a large number of carboxyl, hydroxyl, epoxy, and other active functional groups, which induces good water-solubility and biocompatibility of GO $(76,77)$. Lu et al. reported that the relative survival rate of cells was nearly $100 \%$ even with $100 \mathrm{mg} / \mathrm{L}$ of Go, indicating good biosafety levels of GO in the cell type tested (78). Several studies have shown that cytotoxicity of GO can decrease after modification with biocompatible substances such as PEG, chitosan (79-81). Kai et al. functionalized graphene with PEG, and PEGylated graphene showed high tumor uptake in several xenograft tumor mouse models, which denoted no obvious side effect (82). Zhuang et al. functionalized GO with PEG, which was stable in various biological solutions and showed no obvious increase of apoptosis even at very high concentrations in HCT116 cells (83). Sowmya et al. reported that few-layer graphene didn't elicit cell death on primary macrophages (84). Marco et al. investigated the effects of large and small GO on human peripheral blood mononuclear cells (PBMCs), and there are no significant differences in human PBMCs viability by the exposure to both GO types (85). Sayan et al. reported that GO-PEG-DSPE was meaningfully toxic to U251 but not toxic to normal cells, and the differences could be due to the specific receptors on the surface of glioma cells (86). Portioli et al. directly injected GO in mice brains and assessed the induction of acute neuroinflammatory and neurotoxic effects locally and distantly from the injection site one week post-administration (87). Compared to the liposome group, none of the GO group's mice induced either neuroinflammatory or neurotoxic effects, and only moderate activation of proinflammatory makers was induced at the molecular level in the GO group. However, GO nanocarriers have a toxicity hazard depending on the route of administration, the dose to be administered, the method of synthesis of GO, and its physicochemical properties, which needs an in-depth, thorough evaluation in different animal models (57). Cao et al. reported that GO could be taken into 
human umbilical vein endothelial cells (HUVEC) leading to cytotoxic effects by activation of endoplasmic reticulum (ER) stress and pyroptosis genes (58). Inhalation, ingestion, and dermal are the major routes of entry of GO, and intravenous $\mathrm{GO}$ is distributed mainly in the lungs, liver, and spleen (57). GO and rGO exhibit potential toxicity in non-target organs in laboratory mammals, including liver, lung, spleen, kidney, and reproductive organs, which need further investigation (62).

\section{APPLICATION OF GRAPHENE OXIDE NANOCARRIERS IN THE TREATMENT OF GLIOMA}

\subsection{Direct Killing of Graphene Oxide}

In their traditional applications and understanding, GO and rGO are known as excellent drug nanocarriers. Slawomir et al. have shown that both GO and rGO have a direct killing effect on gliomas and that rGO has a stronger killing effect through inducing apoptosis of glioma cells in vitro and in vivo $(88,89)$. GO has anti-proliferative and anti-migratory effects in gliomas. Maciej et al. postulated that the underlying mechanism of GO is related to its effect on the expression of oxidative phosphorylation genes in glioblastoma U87 cell line (90). In addition, Mateusz et al. showed that GO can decrease migration and invasiveness of gliomas by impairing extracellular adhesion and regulating adhesion-dependent pathways, such as EGFR/ $\mathrm{AKT} / \mathrm{mTOR}$ and $\beta$-catenin in two glioblastoma cell lines, U87 and U118 (91). Tian et al. showed that GO can retard migration by direct disruption of actin filaments in vitro, which is a novel application of GO (92). Xu et al. found that GO may damage the integrity and function of the cell membrane in vitro and in vivo by downregulating cytoskeleton-related genes, such as Actg2, Tubb2a, and Neb (43). In another study, Mateusz et al. showed that GO can inhibit the angiogenesis and tumor microenvironment of U87 (p53 wild) but not U118 (p53 mutant) via the NF- $\mathrm{KB}$ pathway, indicating that the regulation of gliomas by GO is related to the status of p53 (93). Glioblastoma stem-like cells (GSCs) contribute to the selfrenewal and rapid growth of glioblastoma and likely drive the onset of tumor growth, therapeutic resistance, and tumor recurrence. Marco et al. reported that GO could induce GSCs differentiation in vitro by inhibiting several signal transduction pathways (WNT/ $\beta$-catenin, Notch, and JAK-STAT) (94). Wang et al. found that GO induces cell cycle arrest and differentiation of GSCs by epigenetic regulation of GSCs, thereby inhibiting the growth of gliomas in vitro and in vivo (95). GO exerts an antiglioma effect by anti-proliferation, anti-migration, antiangiogenesis, and anti-GSC actions; nonetheless, the exact mechanisms still require further research. Jaroslaw et al. revealed that $\mathrm{rGO}$ can promote the apoptosis of gliomas through caspase- and mitochondrion-dependent apoptotic pathways and has a direct killing effect on gliomas in glioblastoma U87 cell line (96). In another study, Jaroslaw found that $\mathrm{rGO}$ could reduce the expression of voltage- dependent ion channel genes and extracellular receptors in U87 cells, and induce the damage of cell membrane and the changes the of cell membrane potential (97). However, rGO was shown not to specifically distribute to gliomas and rather agglomerated after reaching the gliomas, thus affecting its antitumor function. Ewa et al. used arginine (Arg) to modify rGO to enhance its specific distribution around gliomas and avoid rGO agglomeration in vivo with GBM tumors cultured on chicken embryo chorioallantoic membranes. Following the modification, rGO-Arg was found to block MDM2 expression and upregulate NQO1 expression, thereby optimizing its effect on gliomas (98). However, further in vivo experiments are still needed.

\subsection{Graphene Oxide Nanocarriers as Drug Delivery Systems}

GO and rGO are the most commonly described drug delivery nanocarriers having abundant oxygen-containing groups. The ideal target agent carrier should have four characteristics: targeting desired cells, controlled drug release, non-toxic to normal cells, and biodegradable. For intracranial tumors, one of the common obstacles is delivery of chemotherapy drugs to the tumor site owing to the presence of the blood-brain barrier (BBB) (99). GO can penetrate the BBB, and increase drug accumulation through EPR in gliomas (46, 47, 100-102). Increasing systemic circulation time of GO with high plasma concentration decreases reticuloendothelial system (RES) clearance and reduces drug accumulation in the normal organs to reduce toxicity and to enhance the EPR effect (103). Carmustine [1,3-bis(2-chloroethyl)1 -nitrosourea (BCNU)] is a chemotherapeutic drug commonly used to treat glioma. GO can be modified with polyacrylic acid (PAA) to improve its aqueous solubility and increase cell penetration efficacy. Lu et al. found that PAA-GO covalently combined with BCNU significantly prolonged the half-life of BCNU and effectively increased the intracellular drug concentration, thereby enhancing apoptosis of glioma cells in vitro (104). Wang et al. used PF127 to modify GO to enhance its water solubility and obtained PF127-GO-DOX, which significantly enhanced the tumor growth inhibition of glioma compared with pure DOX in glioblastoma U251 cell line (39). Lucanthone (Luc), APE-1 (Apurinic endonuclease-1) inhibitor, can reverse the glioma cell resistance to radiation and chemotherapy in vivo and in vitro (105-107). Sayan et al. coated GO with DSPE-PEG to load Luc, which significantly induced the cell death in glioblastoma U251 cell line (86). Modified GO can produce several killing effects against tumors, and the most common combination is chemo-photothermal therapy. Wang et al. designed a multifunctional platform based on GO, and the platform combined chemo-photothermal therapy, MRI targeting, and glioma targeting together, which provided a perspective way for glioma therapy in vitro and in vivo (108). Yang et al. modified GO with PEG and EGFR antibody to carry epirubicin (EPI), which significantly prolonged the survival of mice with glioma, and the treatment strategy included chemotherapy and photothermal therapy (109). Nucleolin is one of the major nuclear proteins, but it is overexpressed on the membranes of glioma cells and vascular endothelial cells, 
which makes it a promising target (110-113). AS1411 is a DNA aptamer rich in guanine, which can specifically bind to Nucleolin, and has good tumor targeting to anti-glioma (114). Du et al. coated GO with AS1411 to load B3, a berberine derivative, and proved the nanocarrier a promising treatment for tumors (115).

GO can also achieve targeted therapy of tumors through appropriate modification, including molecular targeting, external magnetic field targeting, and other targeting forms. Lactoferrin (Lf) is an iron-transporting serum glycoprotein that binds to receptors overexpressed on the surface of glioma cells and vascular endothelial cells of the BBB. Song et al. established the GO-Fe3O4-DOX delivery system and systematically evaluated its anti-glioma effect. The system was reported to prolong the action of DOX and increase uptake of the molecule by glioma cells, which displayed stronger cytotoxicity against C6 glioma cells (116). Angiopep-2 (ANG-2), a polypeptide and a specific ligand for the low-density lipoprotein receptor-related protein-1 (LRP-1), has a strong ability to pass through the BBB and has a high transcytosis capacity; it can act as a target to increase the ability to deliver drugs to the brain (117). Zhao et al. modified GO with ANG-2 and then attached DOX to the carrier system. The resulting nanocarriers more significantly enhanced tumor growth inhibition than DOX or DOX-GO both in vitro and in vivo (118). The glioma cell line U87-MG with high expression levels of EGFR on the surface is an optimized model for targeting by cetuximab (CET), an EGFR antibody. Lu et al. attached irinotecan (CPT-11) onto GO-CET and then added chitosang-poly(N-isopropylacrylamide) (CPN), a thermosensitive gel, and subsequently entrapped stomatin-like protein 2 (SLP2) short hairpin RNA (shRNA). The final GO-CET-CPT11shRNA-CPN nanocarrier system targeted gliomas with a high expression level of EGFR, formed a hydrogel in the tumor area, prolonged the duration of action of CPT11, and induced cells apoptosis both in vitro and in vivo (119). This system was found to perform dual functions in chemotherapy and gene therapy, thus broadening the treatment options of glioma. The glioma surface is rich in folic acid (FA) receptors. Therefore, Wang et al. added FA and TMZ to GO and the system showed a $\mathrm{pH}$ dependent response as well as sustained release properties after reaching the glioma area, effectively reducing the drug dose and prolonging its duration of action in vitro (120). Transferrin (Tf)mediated transport has been proven to cross the blood-brain barrier, which makes Tf a potential molecular therapeutic target in the treatment in the treatment of glioma (121). In addition, Tf receptors are overexpressed on the surface of glioma cells (122). Hence, Liu et al. used Tf as a target functional group and DOX as a chemotherapeutic drug to construct a new type of gliomatargeted Tf-PEG-GO-DOX nanocarrier delivery system. In vivo experiments showed that the Tf-PEG-GO-DOX system effectively increased the intratumoral concentration of DOX and significantly prolonged the survival period of tumorbearing rats, indicating that the system could effectively improve the efficacy of glioma treatment (123). CTX, a peptide of scorpion venom, has high selectivity for gliomas by binding to matrix metalloproteinase-2 (124). Consequently, Wang et al. modified GO with CTX and loaded DOX to form
CTX-GO-DOX nanocarriers, which significantly increased the concentration of DOX in the tumor cells and ultimately enhanced the killing effect of the drug against C6 glioma cells in vitro (35). CTX-GO is, therefore, a promising drug delivery system for the targeting of gliomas. GO-Fe3O4 can be used for targeted delivery through a magnetic field; it can release the loaded drug in this field to induce the desired therapeutic effect. Wang et al. used GO-Fe3O4 to load TMZ and yielded the GOFe3O4-TMZ system, which was controlled by an external magnetic field and had a strong drug-loading capacity for TMZ with a strong killing effect on C6 glioma cells in vitro (125). External magnetic field targeting with GO can play a role not only in targeted drug delivery but also in auxiliary imaging. Sakine et al. modified GO with superparamagnetic iron oxide nanoparticles (SPION) and poly(lactic-co-glycolic acid) (PLGA) and then attached the radiosensitizing drug IUdR on it to form IUdR-GO-SPION-PLGA. The latter system was enriched in gliomas with the use of an external magnetic field during in vivo experiments and reported to significantly strengthen the apoptosis-inducing effect of IUdR during glioma radiotherapy when monitored under MRI $(126,127)$. This system can increase the therapeutic effect of IUdR, effectively reduce its dosage, and in turn reduce its toxicity to healthy biological tissues. There are a variety of other modified groups that are used to target gliomas, and the effectiveness of these groups is worthy of further exploration.

\subsection{Immunotherapy of Graphene Oxide Nanocarriers}

Tumor immunotherapy is mainly based on the relationship between the immune function of the body and the status of tumors, and it is important to find optimized intervention measures to regulate the body's immune response to tumors to achieve anti-tumor effects (128). Dendritic cells (DCs) are the most important antigen-presenting cells known in current research to date. Under normal circumstances, there are very small amounts of DCs in the human body. Only once DCs can normally perform the antigen-presenting function can the body effectively recognize the pathogen, induce an immune response, and produce a normal immune response (129). DCs in cancer patients are defective and cannot present tumor antigens properly. Reactivating DCs to initiate anti-tumor immune responses has become an important hot spot in tumor immunotherapy in recent years. For central nervous system tumors, activated DCs can simultaneously promote the infiltration of lymphocytes in the tumor microenvironment and monitor the entire central nervous system accurately and specifically (130). GO excels in loading and delivering antigen (Ag). Wang et al. used the glioma peptide Ag from T98G, a human glioma cell line, to modify GO. GO-Ag has been reported to activate DCs in vitro, effectively inducing a specific anti-glioma immune response, promoting the arrival of lymphocytes and significantly upregulating the secretion of interferon- $\gamma$ (IFN- $\gamma$ ) (131). GO-Ag provides a new idea for glioma immunotherapy; it is, therefore, important to find a safe form of $\mathrm{Ag}$ and also a safe form of the composite GO-Ag for use in clinical settings. Lu et al. developed $\mathrm{Fe} 3 \mathrm{O} 4$ nanoparticles (FNPs)-rGO-PEG for used for 
MRI-guided photothermal-immunotherapy, which could activate DCs after laser irradiation in vivo (132). Indoleamine-2,3dioxygenase (IDO) is an immunosuppressive enzyme capable of inhibiting T cells, and IDO inhibitors (IDOi) boost the efficiency of immune-based cancer therapies (133). Yang et al. established PEGrGO-FA-IDOi, which could directly kill tumor cells under laser irradiation and active antitumor immune response in vivo (134).

\subsection{Phototherapy of Graphene Oxide Nanocarriers}

Phototherapy includes photothermal therapy (PTT) and photodynamic therapy (PDT). Photothermal therapy refers to injecting materials with strong light-to-heat conversion properties into the human body, targeting them to the tumor tissues, and irradiating them with a light source to kill tumor cells by converting light energy into heat $(135,136)$. GO is a potential photosensitizer. It can convert light energy into heat energy under $808 \mathrm{~nm}$ near-infrared laser irradiation, with most biological systems not being sensitive to light in this region. Therefore, the use of GO for photothermal treatment can kill tumor cells contactless and non-invasive. Furthermore, it is non-invasive and safer than conventional treatment methods such as surgery, chemotherapy, and radiotherapy $(137,138)$. Samira et al. found that IUdR-GO-SPION-PLGA has radiosensitizing and photothermal treatment effects on gliomas in the near-infrared (NIR)region, significantly increasing the glioma killing effect of IUdR in vitro (139). Li et al. coupled the targeting molecule Tf on the surface of GO to prepare functionalized GO-Tf-FITC microparticles, which were irradiated with infrared rays at 808 $\mathrm{nm}$. Flow cytometry detected the killing effect on glioma U251 cells with GO-Tf-FITC, with the apoptosis and death indices of the GO-Tf-FITC group being significantly higher than those of the GO-FITC and blank control groups. Furthermore, functionalized GO-Tf-FITC were found to have a significant targeted photothermal killing effect on glioma U251 cells when viewed using fluorescence imaging following fluorescence labeling (140). Dong et al. further established GO-PEG-Tf as a drug nanocarrier and loaded it with DOX to perform dual functions in chemotherapy and photothermal therapy. The system showed a great killing effect on gliomas in in vivo and in vitro experiments (141). Omid et al. transformed rGO into reduced graphene oxide nanomeshs (rGONMs) using $\mathrm{TiO}_{2}$, and then used RGD to modify GO targeting of U87-MG to establish rGONM-PEG-Cy7-RGD (142). Owing to the strong NIR absorption ability of rGONMs, this system can significantly improve the absorption capacity of NIR, which enhances the photothermal therapy ability on gliomas. Joshua et al. also established a similar model and further proved that the system is efficient and could be used for effective photothermal therapy using a mouse glioma model with low-dose GO at a low laser power (143). The improvement of photothermal therapy capabilities with GO is also an important direction for future research.

Photodynamic therapy uses photo-biochemical processes to convert light energy into free radicals, which then play a role in inducing programmed cell death (136). U87-MG has been reported to cause an overexpression of integrin $\alpha v \beta 3$ protein receptors (144). Pyropheophorbide-alpha $(\mathrm{PPa})$ is a promising second-generation photosensitizer (145). Wei et al. prepared a GO carrier, $\mathrm{PPa}-\mathrm{GO}-\mathrm{mAb}$, coupled with an integrin $\alpha v \beta 3$ monoclonal antibody as the targeting ligand. The experimental results showed that this nanocarrier system could actively target U87-MG, through gathering around the mitochondria of glioma cells and producing free radicals to exert a killing effect under near-infrared laser irradiation. A CCK8 cytotoxicity test confirmed that the nanocarriers could effectively kill U87-MG cells, and the killing effect was concentration-dependent (146) (Table 2).

TABLE 2 | A brief summary of GO in glioma therapeutic conditions.

\begin{tabular}{|c|c|c|}
\hline Type of application & Graphene complex & Ref. \\
\hline \multirow[t]{10}{*}{ Direct Killing } & GO & (94) \\
\hline & $\mathrm{GO} / \mathrm{rGO}$ & (88) \\
\hline & rGO & (89) \\
\hline & GO & (90) \\
\hline & GO & (91) \\
\hline & GO & (93) \\
\hline & GO & (95) \\
\hline & rGO & (96) \\
\hline & rGO & (97) \\
\hline & rGO-Arg & (98) \\
\hline \multirow[t]{11}{*}{ Drug Delivery } & $\mathrm{GO}-\gamma-\mathrm{Fe}_{2} \mathrm{O}_{3}-\mathrm{CisPt}$ & (147) \\
\hline & Tf-PEG-GO-DOX & (123) \\
\hline & $\mathrm{GO}-\mathrm{Fe}_{3} \mathrm{O}_{4}$-Lf-DOX & (116) \\
\hline & GO-PEG-DSPE-Luc & (86) \\
\hline & GO-Gd-Let-7g-EPI & (148) \\
\hline & PF127-GO-DOX & (39) \\
\hline & PAA-GO-BCNU & (104) \\
\hline & ANG-DOX-GO & (118) \\
\hline & CPN-GO-CET/CPT11-shRNA & (119) \\
\hline & GO-FA-TMZ & (120) \\
\hline & $\mathrm{GO}-\mathrm{Fe}_{3} \mathrm{O}_{4}-\mathrm{TMZ}$ & (125) \\
\hline \multirow[t]{3}{*}{ Immunotherapy } & GO-Ag & (131) \\
\hline & FNPs-rGO-PEG & (132) \\
\hline & PEG-rGO-FA-IDOi & (134) \\
\hline \multirow[t]{6}{*}{ Phototherapy } & rGO-PEG-RGD & (143) \\
\hline & rGONM-PEG-Cy7-RGD & (142) \\
\hline & GO-porphyrin-RGD & (149) \\
\hline & PPa-GO-mAb & (146) \\
\hline & IUdR-GO-SPION-PLGA & (139) \\
\hline & GO-Tf-FITC & (140) \\
\hline \multirow[t]{6}{*}{ Drug Delivery and phototherapy } & rGO-BSA-DOX & (138) \\
\hline & rGO-AuNRVe-DOX & (150) \\
\hline & MGMSPI-PEG-IP-DOX-Fe $\mathrm{O}_{4}$ & (108) \\
\hline & PEG-NGO-C225/EPI & (109) \\
\hline & AS1411-GO/B3 & (115) \\
\hline & GO-PEG-Tf-DOX & (141) \\
\hline
\end{tabular}

GO, Graphene oxide; rGO, reduced Graphene oxide; Arg, arginine; CisPt, Cisplatin; Tf, Transferrin; PEG, Polyethylene glycol; DOX, doxorubicin; Lf, Lactoferrin; DSPE, 1,2Distearoyl-sn-glycero-3-phosphoethanolamine; Luc, Lucanthone; Gd, gadolinium; EPI, epirubicin; PF127, Pluronic F127; PAA, polyacrylic acid; BCNU, 1,3-bis(2-chloroethyl)-1nitrosourea; ANG, Angiopep; CPN, chitosan-g-poly(N-isopropylacrylamide); $C E T$, cetuximab; CPT11, irinotecan; shRNA, short hairpin RNA; FA, Folic acid; TMZ, Temozolomide; Ag, antigen; $F N P \mathrm{Fe}_{3} \mathrm{O}_{4}$, nanoparticle; IDOi, indoleamine-2,3dioxygenase inhibitor; $R G D$, arginine-glycine-aspartic acid; rGONM, reduced graphene oxide nanomesh; Cy7, cyanine 7; PPa, Pyropheophorbide-alpha; mAb, monoclonal antibody; IUdR, 5-iodo-2-deoxyuridine; SPION superparamagnetic iron oxide nanoparticle; PLGA, poly(lactic-co-glycolic acid); FITC, Fluorescein isothiocyanate; BSA, bovine serum albumin; AuNRVe, ultrasmall plasmonic gold nanorod vesicle; MGMSPI, magnetic graphene-mesoporous silica; IP, interleukin-13-based peptide; NGO, nanographene oxide, C225, cetuximab. 


\section{CONCLUSIONS AND PERSPECTIVES}

In general, GO nanocarriers are widely studied in the treatment of gliomas because of their excellent physical and chemical properties and have shown broad application prospects in medicine, such as in chemotherapy, immunotherapy, and phototherapy $(151,152)$. Modified GO nanocarriers have shown long drug action time, good efficacy, low toxic and side effects, high drug loading, acceptable biosafety, easy to achieve controlled release of drugs, and low price, which make them promising drug carriers for clinical applications. Zhu et al. injected docetaxel-GO-CS gel into tumor tissues of mice in vivo, which gained a significantly longer drug action time (153). Pei et al. confirmed that pGO-Pt-DOX presented more therapeutic efficacy and less systemic toxicity than free drugs in vitro and in vivo studies (154). Islami et al. achieved controlled release of quercetin $(\mathrm{Qu})$ with Qu-hyperbranched polyglycerol (HPG)-GO, and Qu-HPG-GO revealed significant improvement in drug loading (155). After further exploration, the potential of GO nanocarriers in the clinical applications of gliomas will be limitless.

At present, the use of GO as a nanocarrier is still in the preliminary stages of research; there are still many problems to be solved, such as the effectiveness and safety of functionally modified GO nanocarriers in the body and their distribution in tumor tissues. GO is more water-soluble than graphene, but it tends to aggregate under physiological conditions, even leading death to mice (156). The modification GO surface can purposefully change its physical and chemical properties and biocompatibility to improve the drug carrier efficiency (53). Covalent modification of $\mathrm{GO}$ often requires multi-step chemical reactions, which may affect the activity of biomolecules, while non-covalent modification can avoid this deficiency, which is only limited to chemical or biological molecules with a specific structure (157). There is still room for improvement in the preparation and modification of GOs, which is worthy of further optimization research. The relationship between GO functionalization and biological system and the mechanism of biological clearance is yet to be completely understood. Key theories for controlling drug release of GO nanocarrier are still immature. The current GO nanocarriers are mainly used for drug loading via non-covalent interactions, which makes the drug loading amount unstable, and the drug loading stability of the GO nanocarriers is even more debatable (158). GO could

\section{REFERENCES}

1. Lapointe S, Perry A, Butowski N. Primary Brain Tumours in Adults. Lancet (London England) (2018) 392(10145):432-46. doi: 10.1016/S0140-6736(18) 30990-5

2. Weller M, van den Bent M, Preusser M, Le Rhun E, Tonn J, Minniti G, et al. EANO Guidelines on the Diagnosis and Treatment of Diffuse Gliomas of Adulthood. Nat Rev Clin Oncol (2021) 18(3):170-86. doi: 10.1038/s41571020-00447-z

3. Tan A, Ashley D, López G, Malinzak M, Friedman H, Khasraw M. Management of Glioblastoma: State of the Art and Future Directions. CA: Cancer J Clin (2020) 70(4):299-312. doi: 10.3322/caac.21613

4. Stupp R, Mason W, van den Bent M, Weller M, Fisher B, Taphoorn M, et al. Radiotherapy Plus Concomitant and Adjuvant Temozolomide for passively accumulate to glioma tissue due to the EPR effect (24). Besides passive targeting such as EPR, practicing active targeting will improve clinical practicability. Hence, its targeting still needs to be improved and optimized. In addition, multifunctional and multi-target modifications of GO nanocarriers to improve the specificity of targeting gliomas and prolonging the retention time in tumors should also be the focus of future research, such as a combination of chemotherapy, immunotherapy, and phototherapy (152). After the release of loaded drugs, the elimination of GO in the body is also an issue that must be paid attention to in cancer therapy (159). GO is mainly used to load small molecule drugs, but not biomacromolecules such as DNA and protein, and a number of studies on GO are carried out in vitro for the potentially harmful effects, lacking in vivo experimental data $(119,160)$. At present, many studies of GO nanocarriers focus on classical chemotherapy drugs, anti-tumor traditional Chinese medicine components, and gene drugs. Further research is needed to improve the diversity of loaded substances and explore in vivo processes (161). In conclusion, there are still many problems in the study of GO, which requires scientific research teams to strengthen disciplinary integration and jointly solve the difficulties.

\section{AUTHOR CONTRIBUTIONS}

BW carried out the primary literature search, drafted and revised the manuscript, and participated in discussions. HG, HY, YC, HX, and GZ helped modify the manuscript. All authors read and approved the final manuscript.

\section{FUNDING}

We acknowledge the funding support from National Nature and Science Foundation of China (Grant Number: 81772684), the S\&T Development Planning Program of Jilin Province (Grant Number: 20200201469JC, 20200201613JC, 20200404101YY, and 20200201388JC), and Foundation from the Development and Reform Commission of Jilin Province (Grant Number: 2017C059-2, 2017C059-5, and Chinese People's Brain Neural Network Research and Innovation Cooperation Platform Construction Project).

Glioblastoma. N Engl J Med (2005) 352(10):987-96. doi: 10.1056/ NEJMoa043330

5. Khaddour K, Johanns T, Ansstas G. The Landscape of Novel Therapeutics and Challenges in Glioblastoma Multiforme: Contemporary State and Future Directions. Pharmaceuticals (Basel Switzerland) (2020) 13(11):389. doi: $10.3390 / \mathrm{ph} 13110389$

6. Finch A, Solomou G, Wykes V, Pohl U, Bardella C, Watts C. Advances in Research of Adult Gliomas. Int J Mol Sci (2021) 22(2):924. doi: 10.3390/ijms22020924

7. Luo Y, Hou W, Zeng L, Li Z, Ge W, Yi C, et al. Progress in the Study of Markers Related to Glioma Prognosis. Eur Rev Med Pharmacol Sci (2020) 24 (14):7690-7. doi: 10.26355/eurrev_202007_22271

8. Kristensen B, Priesterbach-Ackley L, Petersen J, Wesseling P. Molecular Pathology of Tumors of the Central Nervous System. Ann Oncol Off J Eur Soc Med Oncol (2019) 30(8):1265-78. doi: 10.1093/annonc/mdz164 
9. Picart T, Berhouma M, Dumot C, Pallud J, Metellus P, Armoiry X, et al. Optimization of High-Grade Glioma Resection Using 5-ALA FluorescenceGuided Surgery: A Literature Review and Practical Recommendations From the Neuro-Oncology Club of the French Society of Neurosurgery. NeuroChirurgie (2019) 65(4):164-77. doi: 10.1016/j.neuchi.2019.04.005

10. Meaney C, Stastna M, Kardar M, Kohandel M. Spatial Optimization for Radiation Therapy of Brain Tumours. PloS One (2019) 14(6):e0217354. doi: 10.1371/journal.pone.0217354

11. Luo C, Xu S, Dai G, Xiao Z, Chen L, Liu Z. Tumor Treating Fields for HighGrade Gliomas. Biomed Pharmacother $=$ Biomed Pharmacother (2020) 127:110193. doi: 10.1016/j.biopha.2020.110193

12. Yang W, Wu G, Barth R, Swindall M, Bandyopadhyaya A, Tjarks W, et al. Molecular Targeting and Treatment of Composite EGFR and EGFRvIIIPositive Gliomas Using Boronated Monoclonal Antibodies. Clin Cancer Res an Off J Am Assoc Cancer Res (2008) 14(3):883-91. doi: 10.1158/10780432.CCR-07-1968

13. Han S, Liu Y, Cai S, Qian M, Ding J, Larion M, et al. IDH Mutation in Glioma: Molecular Mechanisms and Potential Therapeutic Targets. $\mathrm{Br} \mathrm{J}$ Cancer (2020) 122(11):1580-9. doi: 10.1038/s41416-020-0814-x

14. Lim M, Xia Y, Bettegowda C, Weller M. Current State of Immunotherapy for Glioblastoma. Nat Rev Clin Oncol (2018) 15(7):422-42. doi: 10.1038/s41571018-0003-5

15. Wang J, Bao Y, Yao Y. Application of Bionanomaterials in Tumor Immune Microenvironment Therapy. J Immunol Res (2021) 2021:6663035. doi: $10.1155 / 2021 / 6663035$

16. Hui Y, Yi X, Hou F, Wibowo D, Zhang F, Zhao D, et al. Role of Nanoparticle Mechanical Properties in Cancer Drug Delivery. ACS Nano (2019) 13 (7):7410-24. doi: 10.1021/acsnano.9b03924

17. Liu G, Lovell J, Zhang L, Zhang Y. Stimulus-Responsive Nanomedicines for Disease Diagnosis and Treatment. Int J Mol Sci (2020) 21(17):6380. doi: $10.3390 /$ ijms 21176380

18. Li X, Li W, Wang M, Liao Z. Magnetic Nanoparticles for Cancer Theranostics: Advances and Prospects. J Control Release Off J Control Release Soc (2021) 335:437-48. doi: 10.1016/j.jconrel.2021.05.042

19. Barbarisi M, Iaffaioli R, Armenia E, Schiavo L, De Sena G, Tafuto S, et al. Novel Nanohydrogel of Hyaluronic Acid Loaded With Quercetin Alone and in Combination With Temozolomide as New Therapeutic Tool, CD44 Targeted Based, of Glioblastoma Multiforme. J Cell Physiol (2018) 233 (10):6550-64. doi: 10.1002/jcp.26238

20. Zuchowska A, Jastrzebska E, Mazurkiewicz-Pawlicka M, Malolepszy A, Stobinski L, Trzaskowski M, et al. Well-Defined Graphene Oxide as a Potential Component in Lung Cancer Therapy. Curr Cancer Drug Targets (2020) 20(1):47-58. doi: 10.2174/1568009619666191021113807

21. Singh G, Nenavathu B, Imtiyaz K, Moshahid A Rizvi M. Fabrication of Chlorambucil Loaded Graphene- Oxide Nanocarrier and Its Application for Improved Antitumor Activity. Biomed Pharmacother $=$ Biomed Pharmacother (2020) 129:110443. doi: 10.1016/j.biopha.2020.110443

22. Sharma H, Mondal S. Functionalized Graphene Oxide for Chemotherapeutic Drug Delivery and Cancer Treatment: A Promising Material in Nanomedicine. Int J Mol Sci (2020) 21(17):6280. doi: 10.3390/ ijms 21176280

23. Lamb J, Fischer E, Rosillo-Lopez M, Salzmann C, Holland J. MultiFunctionalised Graphene Nanoflakes as Tumour-Targeting Theranostic Drug-Delivery Vehicles. Chem Sci (2019) 10(38):8880-8. doi: 10.1039/ C9SC03736E

24. Zhang Y, Sun T, Jiang C. Biomacromolecules as Carriers in Drug Delivery and Tissue Engineering. Acta Pharm Sin B (2018) 8(1):34-50. doi: 10.1016/ j.apsb.2017.11.005

25. Shariare M, Masum A, Alshehri S, Alanazi F, Uddin J, Kazi M. Preparation and Optimization of PEGylated Nano Graphene Oxide-Based Delivery System for Drugs With Different Molecular Structures Using Design of Experiment (DoE). Molecules (Basel Switzerland) (2021) 26(5):1457. doi: 10.3390/molecules26051457

26. Liu T, Li J, Wu X, Zhang S, Lu Z, Li G, et al. Transferrin-Targeting Redox Hyperbranched Poly(Amido Amine)-Functionalized Graphene Oxide for Sensitized Chemotherapy Combined With Gene Therapy to Nasopharyngeal Carcinoma. Drug Deliv (2019) 26(1):744-55. doi: $10.1080 / 10717544.2019 .1642421$
27. Chen H, Xing L, Guo H, Luo C, Zhang X. Dual-Targeting SERS-Encoded Graphene Oxide Nanocarrier for Intracellular Co-Delivery of Doxorubicin and 9-Aminoacridine With Enhanced Combination Therapy. Analyst (2021) 146(22):6893-901. doi: 10.1039/D1AN01237A

28. Huang X, Zhang J, Song Y, Zhang T, Wang B. Combating Liver Cancer Through GO-Targeted Biomaterials. Biomed Mater (Bristol Engl) (2021) 16 (6):065003. doi: $10.1088 / 1748-605 X / a c 1 f 72$

29. Wang J, Han S, Zhang Z, Wang J, Zhang G. Preparation and Performance of Chemotherapy Drug-Loaded Graphene Oxide-Based Nanosheets That Target Ovarian Cancer Cells via Folate Receptor Mediation. J Biomed Nanotechnol (2021) 17(5):960-70. doi: 10.1166/jbn.2021.3080

30. Wang Y, Sun G, Gong Y, Zhang Y, Liang X, Yang L. Functionalized FolateModified Graphene Oxide/PEI siRNA Nanocomplexes for Targeted Ovarian Cancer Gene Therapy. Nanoscale Res Lett (2020) 15(1):57. doi: 10.1186/ s11671-020-3281-7

31. Cao X, Zheng S, Zhang S, Wang Y, Yang X, Duan H, et al. Functionalized Graphene Oxide With Hepatocyte Targeting as Anti-Tumor Drug and Gene Intracellular Transporters. J Nanosci Nanotechnol (2015) 15(3):2052-9. doi: 10.1166/jnn.2015.9145

32. Ou L, Sun T, Liu M, Zhang Y, Zhou Z, Zhan X, et al. Efficient miRNA Inhibitor Delivery With Graphene Oxide-Polyethylenimine to Inhibit Oral Squamous Cell Carcinoma. Int J Nanomed (2020) 15:1569-83. doi: 10.2147/ IJN.S220057

33. Zhang B, Yu Q, Zhang Y, Liu Y. Two-Dimensional Supramolecular Assemblies Based on $\beta$-Cyclodextrin-Grafted Graphene Oxide for Mitochondrial Dysfunction and Photothermal Therapy. Chem Commun (Cambridge England) (2019) 55(81):12200-3. doi: 10.1039/C9CC05727G

34. Li Y, Zheng L, Xiao L, Wang L, Cui J, Sha D, et al. Eco-Friendly Development of an Ultrasmall IONP-Loaded Nanoplatform for Bimodal Imaging-Guided Cancer Theranostics. Biomater Sci (2020) 8(22):6375-86. doi: 10.1039/ D0BM00867B

35. Wang H, Gu W, Xiao N, Ye L, Xu Q. Chlorotoxin-Conjugated Graphene Oxide for Targeted Delivery of an Anticancer Drug. Int J Nanomed (2014) 9:1433-42. doi: 10.2147/IJN.S58783

36. Li Y, Yang Y, Shao Y, Sun Y, Si H, Miao J, et al. Chitosan Functionalized Graphene Oxide Nanocomposites for Fluorescence Imaging of Apoptotic Processes and Targeted Anti-Inflammation Study. Carbohydr Polymers (2021) 269:118345. doi: 10.1016/j.carbpol.2021.118345

37. Kavitha T, Kang I, Park S. Poly(N-Vinyl Caprolactam) Grown on Nanographene Oxide as an Effective Nanocargo for Drug Delivery. Colloids Surfaces B Biointerfaces (2014) 115:37-45. doi: 10.1016/j.colsurfb.2013.11.022

38. Hwang D, Kim H, Li F, Park J, Kim D, Park J, et al. In Vivo Visualization of Endogenous miR-21 Using Hyaluronic Acid-Coated Graphene Oxide for Targeted Cancer Therapy. Biomaterials (2017) 121:144-54. doi: 10.1016/ j.biomaterials.2016.12.028

39. Wang P, Wang X, Tang Q, Chen H, Zhang Q, Jiang H, et al. Functionalized Graphene Oxide Against U251 Glioma Cells and Its Molecular Mechanism. Mater Sci Eng C Mater Biol Appl (2020) 116:111187. doi: 10.1016/ j.msec.2020.111187

40. Ma M, Cheng L, Zhao A, Zhang H, Zhang A. Pluronic-Based Graphene Oxide-Methylene Blue Nanocomposite for Photodynamic/Photothermal Combined Therapy of Cancer Cells. Photodiagn Photodyn Ther (2020) 29:101640. doi: 10.1016/j.pdpdt.2019.101640

41. Qu Y, Sun F, He F, Yu C, Lv J, Zhang Q, et al. Glycyrrhetinic Acid-Modified Graphene Oxide Mediated siRNA Delivery for Enhanced Liver-Cancer Targeting Therapy. Eur J Pharm Sci Off J Eur Fed Pharm Sci (2019) 139:105036. doi: 10.1016/j.ejps.2019.105036

42. Zhang Q, Huang X, Pu Y, Yi Y, Zhang T, Wang B. pH-Sensitive and Biocompatible Quercetin-Loaded GO-PEA-HA Carrier Improved Antitumour Efficiency and Specificity. Artif Cells Nanomed Biotechnol (2018) 46:S28-37. doi: 10.1080/21691401.2018.1489261

43. Xu M, Zhu J, Wang F, Xiong Y, Wu Y, Wang Q, et al. Improved In Vitro and In Vivo Biocompatibility of Graphene Oxide Through Surface Modification: Poly(Acrylic Acid)-Functionalization Is Superior to PEGylation. ACS nano (2016) 10(3):3267-81. doi: 10.1021/acsnano.6b00539

44. Syama S, Mohanan PV. Comprehensive Application of Graphene: Emphasis on Biomedical Concerns. Nanomicro Lett (2019) 11(1):6. doi: 10.1007/ s40820-019-0237-5 
45. Garnier L, Gkountidi AO, Hugues S. Tumor-Associated Lymphatic Vessel Features and Immunomodulatory Functions. Front Immunol (2019) 10:720. doi: 10.3389/fimmu.2019.00720

46. Mariadoss A, Saravanakumar K, Sathiyaseelan A, Wang M. Preparation, Characterization and Anti-Cancer Activity of Graphene Oxide--Silver Nanocomposite. J Photochem Photobiol B Biol (2020) 210:111984. doi: 10.1016/j.jphotobiol.2020.111984

47. Chai D, Hao B, Hu R, Zhang F, Yan J, Sun Y, et al. Delivery of Oridonin and Methotrexate via PEGylated Graphene Oxide. ACS Appl Mater Interf (2019) 11(26):22915-24. doi: 10.1021/acsami.9b03983

48. Nakamura Y, Mochida A, Choyke P, Kobayashi H. Nanodrug Delivery: Is the Enhanced Permeability and Retention Effect Sufficient for Curing Cancer? Bioconjugate Chem (2016) 27(10):2225-38. doi: 10.1021/ acs.bioconjchem.6b00437

49. Editorial. Challenging Paradigms in Tumour Drug Delivery. Nat Mater (2020) 19(5):477. doi: 10.1038/s41563-020-0676-x

50. Wilhelm S, Tavares AJ, Dai Q, Ohta S, Audet J, Dvorak HF, et al. Analysis of Nanoparticle Delivery to Tumours. Nat Rev Mater (2016) 1(5):1-12. doi: 10.1038/natrevmats.2016.14

51. Zhao M, van Straten D, Broekman MLD, Préat V, Schiffelers RM. Nanocarrier-Based Drug Combination Therapy for Glioblastoma. Theranostics (2020) 10(3):1355-72. doi: 10.7150/thno.38147

52. Danhier F. To Exploit the Tumor Microenvironment: Since the EPR Effect Fails in the Clinic, What Is the Future of Nanomedicine? J Control Release Off J Control Release Soc (2016) 244:108-21. doi: 10.1016/j.jconrel. 2016.11.015

53. Daniyal M, Liu B, Wang W. Comprehensive Review on Graphene Oxide for Use in Drug Delivery System. Curr Med Chem (2020) 27(22):3665-85. doi: $10.2174 / 13816128256661902011296290$

54. Shahmoradi S, Golzar H, Hashemi M, Mansouri V, Omidi M, Yazdian F, et al. Optimizing the Nanostructure of Graphene Oxide/Silver/Arginine for Effective Wound Healing. Nanotechnology (2018) 29(47):475101. doi: 10.1088/1361-6528/aadedc

55. Jiang W, Chen J, Gong C, Wang Y, Gao Y, Yuan Y. Intravenous Delivery of Enzalutamide Based on High Drug Loading Multifunctional Graphene Oxide Nanoparticles for Castration-Resistant Prostate Cancer Therapy. J Nanobiotechnol (2020) 18(1):50. doi: 10.1186/s12951-020-00607-4

56. Trusek A, Kijak E, Granicka L. Graphene Oxide as a Potential Drug Carrier Chemical Carrier Activation, Drug Attachment and Its Enzymatic Controlled Release. Mater Sci Eng C Mater Biol Appl (2020) 116:111240. doi: 10.1016/j.msec.2020.111240

57. Rhazouani A, Gamrani H, El Achaby M, Aziz K, Gebrati L, Uddin M, et al. In VitroSynthesis and Toxicity of Graphene Oxide Nanoparticles: A Literature Review of and Studies. BioMed Res Int (2021) 2021:5518999. doi: 10.1155/2021/5518999

58. Cao Y, Xiao W, Li S, Qiu D. A Comparative Study of Toxicity of Graphdiyne and Graphene Oxide to Human Umbilical Vein Endothelial Cells. J Appl Toxicol JAT (2021) 41(12):2021-30. doi: 10.1002/jat.4182

59. Jaworski S, Strojny-Cieślak B, Wierzbicki M, Kutwin M, Sawosz E, Kamaszewski M, et al. Comparison of the Toxicity of Pristine Graphene and Graphene Oxide, Using Four Biological Models. Mater (Basel Switzerland) (2021) 14(15):4250. doi: 10.3390/ma14154250

60. Seabra A, Paula A, de Lima R, Alves O, Durán N. Nanotoxicity of Graphene and Graphene Oxide. Chem Res Toxicol (2014) 27(2):159-68. doi: 10.1021/ tx400385x

61. Palmieri V, Perini G, De Spirito M, Papi M. Graphene Oxide Touches Blood: In Vivo Interactions of Bio-Coronated 2D Materials. Nanoscale Horizons (2019) 4(2):273-90. doi: 10.1039/C8NH00318A

62. Ema M, Gamo M, Honda K. A Review of Toxicity Studies on GrapheneBased Nanomaterials in Laboratory Animals. Regul Toxicol Pharmacol RTP (2017) 85:7-24. doi: 10.1016/j.yrtph.2017.01.011

63. Shin Y, Vranic S, Just-Baringo X, Gali S, Kisby T, Chen Y, et al. Stable, Concentrated, Biocompatible, and Defect-Free Graphene Dispersions With Positive Charge. Nanoscale (2020) 12(23):12383-94. doi: 10.1039/ D0NR02689A

64. Yi L, Zhang Y, Shi X, Du X, Wang X, Yu A, et al. Recent Progress of Functionalised Graphene Oxide in Cancer Therapy. J Drug Target (2019) 27 (2):125-44. doi: 10.1080/1061186X.2018.1474359
65. Jafari Z, Baharfar R, Rad A, Asghari S. Potential of Graphene Oxide as a Drug Delivery System for Sumatriptan: A Detailed Density Functional Theory Study. J Biomol Struct Dyn (2021) 39(5):1611-20. doi: 10.1080/ 07391102.2020.1736161

66. de Sousa M, Martins C, Franqui L, Fonseca L, Delite F, Lanzoni E, et al. Covalent Functionalization of Graphene Oxide With D-Mannose: Evaluating the Hemolytic Effect and Protein Corona Formation. J Mater Chem B (2018) 6(18):2803-12. doi: 10.1039/C7TB02997G

67. Ouyang A, Zhao D, Wang X, Zhang W, Jiang T, Li A, et al. Covalent RGDGraphene-Phthalocyanine Nanocomposite for Fluorescence ImagingGuided Dual Active/Passive Tumor-Targeted Combinatorial Phototherapy. J Mater Chem B (2021) 10(2):306-20. doi: 10.1039/D1TB02254G

68. Neelgund G, Oki A, Bandara S, Carson L. Photothermal Effect and Cytotoxicity of CuS Nanoflowers Deposited Over Folic Acid Conjugated Nanographene Oxide. J Materials Chem B (2021) 9(7):1792-803. doi: 10.1039/D0TB02366C

69. Zhuang W, He L, Wang K, Ma B, Ge L, Wang Z, et al. Combined Adsorption and Covalent Linking of Paclitaxel on Functionalized Nano-Graphene Oxide for Inhibiting Cancer Cells. ACS Omega (2018) 3(2):2396-405. doi: 10.1021/ acsomega.7b02022

70. Xu H, Fan M, Elhissi AM, Zhang Z, Wan KW, Ahmed W, et al. PEGylated Graphene Oxide for Tumor-Targeted Delivery of Paclitaxel. Nanomed (Lond) (2015) 10(8):1247-62. doi: 10.2217/nnm.14.233

71. Xu Z, Wang S, Li Y, Wang M, Shi P, Huang X. Covalent Functionalization of Graphene Oxide With Biocompatible Poly(Ethylene Glycol) for Delivery of Paclitaxel. ACS Appl Mater Interfaces (2014) 6(19):17268-76. doi: 10.1021/ am505308f

72. More M, Deshmukh P. Development of Amine-Functionalized Superparamagnetic Iron Oxide Nanoparticles Anchored Graphene Nanosheets as a Possible Theranostic Agent in Cancer Metastasis. Drug Deliv Trans Res (2020) 10(4):862-77. doi: 10.1007/s13346-020-00729-0

73. Pan H, Yu Y, Li L, Liu B, Liu Y. Fabrication and Characterization of Taurine Functionalized Graphene Oxide With 5-Fluorouracil as Anticancer Drug Delivery Systems. Nanoscale Res Lett (2021) 16(1):84. doi: 10.1186/s11671021-03541-y

74. Li L, Luo C, Song Z, Reyes-Vargas E, Clayton F, Huang J, et al. Association of Anti-HER2 Antibody With Graphene Oxide for Curative Treatment of Osteosarcoma. Nanomed Nanotechnol Biol Med (2018) 14(2):581-93. doi: 10.1016/j.nano.2017.11.001

75. Zhou L, Wang W, Tang J, Zhou JH, Jiang HJ, Shen J. Graphene Oxide Noncovalent Photosensitizer and Its Anticancer Activity In Vitro. Chemistry (2011) 17(43):12084-91. doi: 10.1002/chem.201003078

76. Qu Z, Jiang Y, Zhang J, Chen S, Zeng R, Zhuo Y, et al. Tailoring OxygenContaining Groups on Graphene for Ratiometric Electrochemical Measurements of Ascorbic Acid in Living Subacute Parkinson's Disease Mouse Brains. Anal Chem (2021) 93(49):16598-607. doi: 10.1021/ acs.analchem.1c03965

77. You P, Yang Y, Wang M, Huang X, Huang X. Graphene Oxide-Based Nanocarriers for Cancer Imaging and Drug Delivery. Curr Pharm Design (2015) 21(22):3215-22. doi: 10.2174/1381612821666150531170832

78. Lu CH, Zhu CL, Li J, Liu JJ, Chen X, Yang HH. Using Graphene to Protect DNA From Cleavage During Cellular Delivery. Chem Commun (Camb) (2010) 46(18):3116-8. doi: 10.1039/b926893f

79. Kazempour M, Namazi H, Akbarzadeh A, Kabiri R. Synthesis and Characterization of PEG-Functionalized Graphene Oxide as an Effective pH-Sensitive Drug Carrier. Artif Cells Nanomed Biotechnol (2019) 47(1):904. doi: 10.1080/21691401.2018.1543196

80. Makvandi P, Ghomi M, Ashrafizadeh M, Tafazoli A, Agarwal T, Delfi M, et al. A Review on Advances in Graphene-Derivative/Polysaccharide Bionanocomposites: Therapeutics, Pharmacogenomics and Toxicity. Carbohydr Polym (2020) 250:116952. doi: 10.1016/j.carbpol.2020.116952

81. Figueroa T, Aguayo C, Fernández K. Design and Characterization of Chitosan-Graphene Oxide Nanocomposites for the Delivery of Proanthocyanidins. Int J Nanomed (2020) 15:1229-38. doi: 10.2147/ IJN.S240305

82. Yang K, Zhang S, Zhang G, Sun X, Lee ST, Liu Z. Graphene in Mice: Ultrahigh In Vivo Tumor Uptake and Efficient Photothermal Therapy. Nano Lett (2010) 10(9):3318-23. doi: 10.1021/nl100996u 
83. Liu Z, Robinson JT, Sun X, Dai H. PEGylated Nanographene Oxide for Delivery of Water-Insoluble Cancer Drugs. J Am Chem Soc (2008) 130 (33):10876-7. doi: 10.1021/ja803688x

84. Malanagahalli S, Murera D, Martín C, Lin H, Wadier N, Dumortier H, et al. Few Layer Graphene Does Not Affect Cellular Homeostasis of Mouse Macrophages. Nanomater (Basel) (2020) 10(2):228. doi: 10.3390/ nano10020228

85. Orecchioni M, Jasim DA, Pescatori M, Manetti R, Fozza C, Sgarrella F, et al. Molecular and Genomic Impact of Large and Small Lateral Dimension Graphene Oxide Sheets on Human Immune Cells From Healthy Donors. Adv Healthc Mater (2016) 5(2):276-87. doi: 10.1002/adhm.201500606

86. Chowdhury SM, Surhland C, Sanchez Z, Chaudhary P, Suresh Kumar MA, Lee S, et al. Graphene Nanoribbons as a Drug Delivery Agent for Lucanthone Mediated Therapy of Glioblastoma Multiforme. Nanomedicine (2015) 11 (1):109-18. doi: 10.1016/j.nano.2014.08.001

87. Portioli C, Bussy C, Mazza M, Lozano N, Jasim D, Prato M, et al. Intracerebral Injection of Graphene Oxide Nanosheets Mitigates Microglial Activation Without Inducing Acute Neurotoxicity: A Pilot Comparison to Other Nanomaterials. Small (Weinheim an der Bergstrasse Germany) (2020) 16(48):e2004029. doi: 10.1002/smll.202004029

88. Jaworski S, Sawosz E, Kutwin M, Wierzbicki M, Hinzmann M, Grodzik M, et al. In Vitro and In Vivo Effects of Graphene Oxide and Reduced Graphene Oxide on Glioblastoma. Int J Nanomed (2015) 10:1585-96. doi: 10.2147/ IJN.S77591

89. Hinzmann M, Jaworski S, Kutwin M, Jagiełło J, Koziński R, Wierzbicki M, et al. Nanoparticles Containing Allotropes of Carbon Have Genotoxic Effects on Glioblastoma Multiforme Cells. Int J Nanomed (2014) 9:2409-17. doi: 10.2147/IJN.S62497

90. Szmidt M, Stankiewicz A, Urbańska K, Jaworski S, Kutwin M, Wierzbicki M, et al. Graphene Oxide Down-Regulates Genes of the Oxidative Phosphorylation Complexes in a Glioblastoma. BMC Mol Biol (2019) 20 (1):2. doi: 10.1186/s12867-018-0119-2

91. Wierzbicki M, Jaworski S, Kutwin M, Grodzik M, Strojny B, Kurantowicz N, et al. Diamond, Graphite, and Graphene Oxide Nanoparticles Decrease Migration and Invasiveness in Glioblastoma Cell Lines by Impairing Extracellular Adhesion. Int J Nanomed (2017) 12:7241-54. doi: 10.2147/ IJN.S146193

92. Tian X, Yang Z, Duan G, Wu A, Gu Z, Zhang L, et al. Graphene Oxide Nanosheets Retard Cellular Migration via Disruption of Actin Cytoskeleton. Small (Weinheim an der Bergstrasse Germany) (2017) 13(3):1602133. doi: $10.1002 / \mathrm{smll} .201602133$

93. Wierzbicki M, Sawosz E, Strojny B, Jaworski S, Grodzik M, Chwalibog A. NF-kb-Related Decrease of Glioma Angiogenic Potential by Graphite Nanoparticles and Graphene Oxide Nanoplatelets. Sci Rep (2018) 8 (1):14733. doi: 10.1038/s41598-018-33179-3

94. Fiorillo M, Verre AF, Iliut M, Peiris-Pagés M, Ozsvari B, Gandara R, et al. Graphene Oxide Selectively Targets Cancer Stem Cells, Across Multiple Tumor Types: Implications for Non-Toxic Cancer Treatment, via "Differentiation-Based Nano-Therapy". Oncotarget (2015) 6(6):3553-62. doi: 10.18632/oncotarget.3348

95. Wang X, Zhou W, Li X, Ren J, Ji G, Du J, et al. Graphene Oxide Suppresses the Growth and Malignancy of Glioblastoma Stem Cell-Like Spheroids via Epigenetic Mechanisms. J Trans Med (2020) 18(1):200. doi: 10.1186/s12967020-02359-z

96. Szczepaniak J, Strojny B, Chwalibog E, Jaworski S, Jagiello J, Winkowska M, et al. Effects of Reduced Graphene Oxides on Apoptosis and Cell Cycle of Glioblastoma Multiforme. Int J Mol Sci (2018) 19(12):3939. doi: 10.3390/ ijms19123939

97. Szczepaniak J, Jagiello J, Wierzbicki M, Nowak D, Sobczyk-Guzenda A, Sosnowska M, et al. Reduced Graphene Oxides Modulate the Expression of Cell Receptors and Voltage-Dependent Ion Channel Genes of Glioblastoma Multiforme. Int J Mol Sci (2021) 22(2):515. doi: 10.3390/ijms22020515

98. Sawosz E, Jaworski S, Kutwin M, Vadalasetty K, Grodzik M, Wierzbicki M, et al. Graphene Functionalized With Arginine Decreases the Development of Glioblastoma Multiforme Tumor in a Gene-Dependent Manner. Int J Mol Sci (2015) 16(10):25214-33. doi: 10.3390/ijms161025214

99. Tang W, Fan W, Lau J, Deng L, Shen Z, Chen X. Emerging Blood-BrainBarrier-Crossing Nanotechnology for Brain Cancer Theranostics. Chem Soc $\operatorname{Rev}(2019)$ 48(11):2967-3014. doi: 10.1039/C8CS00805A
100. He Y, Zhang L, Chen Z, Liang Y, Zhang Y, Bai Y, et al. Enhanced Chemotherapy Efficacy by Co-Delivery of Shabcg2 and Doxorubicin With a $\mathrm{pH}$-Responsive Charge-Reversible Layered Graphene Oxide Nanocomplex. J Mater Chem B (2015) 3(31):6462-72. doi: 10.1039/ С5TB00923E

101. Ngowi E, Wang Y, Qian L, Helmy Y, Anyomi B, Li T, et al. The Application of Nanotechnology for the Diagnosis and Treatment of Brain Diseases and Disorders. Front Bioeng Biotechnol (2021) 9:629832. doi: 10.3389/ fbioe.2021.629832

102. Dalamagkas K, Tsintou M, Seifalian A, Seifalian A. Translational Regenerative Therapies for Chronic Spinal Cord Injury. Int $\mathrm{J} \mathrm{Mol} \mathrm{Sci}$ (2018) 19(6):1776. doi: 10.3390/ijms19061776

103. Sun D, Zhou S, Gao W. What Went Wrong With Anticancer Nanomedicine Design and How to Make It Right. ACS Nano (2020) 14(10):12281-90. doi: 10.1021/acsnano.9b09713

104. Lu Y, Yang H, Hung S, Huang C, Li S, Ma C, et al. Improving Thermal Stability and Efficacy of BCNU in Treating Glioma Cells Using PAAFunctionalized Graphene Oxide. Int J Nanomed (2012) 7:1737-47. doi: 10.2147/IJN.S29376

105. Cho HR, Kumari N, Thakur N, Vu HT, Kim H, Choi SH. Decreased APE-1 by Nitroxoline Enhances Therapeutic Effect in a Temozolomide-Resistant Glioblastoma: Correlation With Diffusion Weighted Imaging. Sci Rep (2019) 9(1):16613. doi: 10.1038/s41598-019-53147-9

106. Hudson AL, Parker NR, Khong P, Parkinson JF, Dwight T, Ikin RJ, et al. Glioblastoma Recurrence Correlates With Increased APE1 and Polarization Toward an Immuno-Suppressive Microenvironment. Front Oncol (2018) 8:314. doi: $10.3389 /$ fonc. 2018.00314

107. Naidu MD, Mason JM, Pica RV, Fung H, Peña LA. Radiation Resistance in Glioma Cells Determined by DNA Damage Repair Activity of Ape1/Ref-1. J Radiat Res (2010) 51(4):393-404. doi: 10.1269/jrr.09077

108. Wang Y, Huang R, Liang G, Zhang Z, Zhang P, Yu S, et al. MRI-Visualized, Dual-Targeting, Combined Tumor Therapy Using Magnetic GrapheneBased Mesoporous Silica. Small (Weinheim an der Bergstrasse Germany) (2014) 10(1):109-16. doi: 10.1002/smll.201301297

109. Yang H, Lu Y, Lin K, Hsu S, Huang C, She S, et al. EGRF Conjugated PEGylated Nanographene Oxide for Targeted Chemotherapy and Photothermal Therapy. Biomaterials (2013) 34(29):7204-14. doi: 10.1016/ j.biomaterials.2013.06.007

110. Kim J, Bae C, Kim M, Song I, Ryu J, Choi J, et al. A Novel Nucleolin-Binding Peptide for Cancer Theranostics. Theranostics (2020) 10(20):9153-71. doi: 10.7150/thno. 43502

111. Galzio R, Rosati F, Benedetti E, Cristiano L, Aldi S, Mei S, et al. Glycosilated Nucleolin as Marker for Human Gliomas. J Cell Biochem (2012) 113(2):5719. doi: $10.1002 /$ jcb. 23381

112. Balça-Silva J, do Carmo A, Tão H, Rebelo O, Barbosa M, Moura-Neto V, et al. Nucleolin Is Expressed in Patient-Derived Samples and Glioblastoma Cells, Enabling Improved Intracellular Drug Delivery and Cytotoxicity. Exp Cell Res (2018) 370(1):68-77. doi: 10.1016/j.yexcr.2018.06.005

113. Darche M, Cossutta M, Caruana L, Houppe C, Gilles M, Habert D, et al. Antagonist of Nucleolin, N6L, Inhibits Neovascularization in Mouse Models of Retinopathies. FASEB J Off Publ Fed Am Soc Exp Biol (2020) 34(4):585162. doi: $10.1096 /$ fj.201901876R

114. Mosafer J, Mokhtarzadeh A. Cell Surface Nucleolin as a Promising Receptor for Effective AS1411 Aptamer-Mediated Targeted Drug Delivery Into Cancer Cells. Curr Drug Deliv (2018) 15(9):1323-9. doi: 10.2174/ 1567201815666180724104451

115. Du P, Yan J, Long S, Xiong H, Wen N, Cai S, et al. Tumor Microenvironment and NIR Laser Dual-Responsive Release of Berberine 9-O-Pyrazole Alkyl Derivative Loaded in Graphene Oxide Nanosheets for Chemo-Photothermal Synergetic Cancer Therapy. J Mater Chem B (2020) 8(18):4046-55. doi: 10.1039/D0TB00489H

116. Song M, Xu H, Liang J, Xiang H, Liu R, Shen Y. Lactoferrin Modified Graphene Oxide Iron Oxide Nanocomposite for Glioma-Targeted Drug Delivery. Mater Sci Eng C Mater Biol Appl (2017) 77:904-11. doi: 10.1016/ j.msec.2017.03.309

117. Oller-Salvia B, Sánchez-Navarro M, Giralt E, Teixidó M. Blood-Brain Barrier Shuttle Peptides: An Emerging Paradigm for Brain Delivery. Chem Soc Rev (2016) 45(17):4690-707. doi: 10.1039/C6CS00076B 
118. Zhao Y, Yin H, Zhang X. Modification of Graphene Oxide by Angiopep-2 Enhances Anti-Glioma Efficiency of the Nanoscaled Delivery System for Doxorubicin. Aging (2020) 12(11):10506-16. doi: 10.18632/aging.103275

119. Lu Y, Lan Y, Chuang C, Lu W, Chan L, Hsu P, et al. Injectable ThermoSensitive Chitosan Hydrogel Containing CPT-11-Loaded EGFR-Targeted Graphene Oxide and SLP2 shRNA for Localized Drug/Gene Delivery in Glioblastoma Therapy. Int J Mol Sci (2020) 21(19):7111. doi: 10.3390/ ijms21197111

120. Wang L, Liu J, Sui L, Zhao P, Ma H, Wei Z, et al. Folate-Modified Graphene Oxide as the Drug Delivery System to Load Temozolomide. Curr Pharm Biotechnol (2020) 21(11):1088-98. doi: 10.2174/1389201021666200226122742

121. Xiao W, Wang Y, Zhang H, Liu Y, Xie R, He X, et al. The Protein Corona Hampers the Transcytosis of Transferrin-Modified Nanoparticles Through Blood-Brain Barrier and Attenuates Their Targeting Ability to Brain Tumor. Biomaterials (2021) 274:120888. doi: 10.1016/j.biomaterials.2021.120888

122. Sun P, Xiao Y, Di Q, Ma W, Ma X, Wang Q, et al. Transferrin ReceptorTargeted PEG-PLA Polymeric Micelles for Chemotherapy Against Glioblastoma Multiforme. Int J Nanomed (2020) 15:6673-88. doi: 10.2147/ IJN.S257459

123. Liu G, Shen H, Mao J, Zhang L, Jiang Z, Sun T, et al. Transferrin Modified Graphene Oxide for Glioma-Targeted Drug Delivery: In Vitro and In Vivo Evaluations. ACS Appl Mater Interf (2013) 5(15):6909-14. doi: 10.1021/ am402128s

124. Sun C, Veiseh O, Gunn J, Fang C, Hansen S, Lee D, et al. In Vivo MRI Detection of Gliomas by Chlorotoxin-Conjugated Superparamagnetic Nanoprobes. Small (Weinheim an der Bergstrasse Germany) (2008) 4 (3):372-9. doi: 10.1002/smll.200700784

125. Wang L, Sui L, Zhao P, Ma H, Liu J, Wei Z, et al. A Composite of Graphene Oxide and Iron Oxide Nanoparticles for Targeted Drug Delivery of Temozolomide. Die Pharm (2020) 75(7):313-7. doi: 10.1691/ph.2020.9170

126. Shirvalilou S, Khoei S, Khoee S, Mahdavi S, Raoufi N, Motevalian M, et al. Enhancement Radiation-Induced Apoptosis in C6 Glioma Tumor-Bearing Rats via $\mathrm{pH}$-Responsive Magnetic Graphene Oxide Nanocarrier. J Photochem Photobiol B Biol (2020) 205:111827. doi: 10.1016/j.jphotobiol. 2020.111827

127. Shirvalilou S, Khoei S, Khoee S, Raoufi N, Karimi M, Shakeri-Zadeh A. Development of a Magnetic Nano-Graphene Oxide Carrier for Improved Glioma-Targeted Drug Delivery and Imaging: In Vitro and In Vivo Evaluations. Chemico-Biol Interact (2018) 295:97-108. doi: 10.1016/ j.cbi.2018.08.027

128. Weller M, Roth P, Preusser M, Wick W, Reardon D, Platten M, et al. Vaccine-Based Immunotherapeutic Approaches to Gliomas and Beyond. Nat Rev Neurol (2017) 13(6):363-74. doi: 10.1038/nrneurol.2017.64

129. Mitchell D, Chintala S, Dey M. Plasmacytoid Dendritic Cell in Immunity and Cancer. J Neuroimmunol (2018) 322:63-73. doi: 10.1016/j.jneuroim.2018. 06.012

130. Garg A, Vara Perez M, Schaaf M, Agostinis P, Zitvogel L, Kroemer G, et al. Trial Watch: Dendritic Cell-Based Anticancer Immunotherapy. Oncoimmunology (2017) 6(7):e1328341. doi: 10.1080/2162402X.2017. 1328341

131. Wang W, Li Z, Duan J, Wang C, Fang Y, Yang X. In Vitro Enhancement of Dendritic Cell-Mediated Anti-Glioma Immune Response by Graphene Oxide. Nanoscale Res Lett (2014) 9(1):311. doi: 10.1186/1556-276X-9-311

132. Wang L, Wang M, Zhou B, Zhou F, Murray C, Towner RA, et al. PEGylated Reduced-Graphene Oxide Hybridized With $\mathrm{Fe}(3) \mathrm{O}(4)$ Nanoparticles for Cancer Photothermal-Immunotherapy. J Mater Chem B (2019) 7(46):740614. doi: $10.1039 / \mathrm{c} 9 \mathrm{tb} 00630 \mathrm{c}$

133. Löb S, Königsrainer A, Rammensee HG, Opelz G, Terness P. Inhibitors of Indoleamine-2,3-Dioxygenase for Cancer Therapy: Can We See the Wood for the Trees? Nat Rev Cancer (2009) 9(6):445-52. doi: 10.1038/nrc2639

134. Yan M, Liu Y, Zhu X, Wang X, Liu L, Sun H, et al. Nanoscale Reduced Graphene Oxide-Mediated Photothermal Therapy Together With IDO Inhibition and PD-L1 Blockade Synergistically Promote Antitumor Immunity. ACS Appl Mater Interfaces (2019) 11(2):1876-85. doi: 10.1021/ acsami.8b 18751

135. Shanmugam V, Selvakumar S, Yeh C. Near-Infrared Light-Responsive Nanomaterials in Cancer Therapeutics. Chem Soc Rev (2014) 43(17):625487. doi: $10.1039 / \mathrm{C} 4 \mathrm{CS} 00011 \mathrm{~K}$
136. Li Q, Hong L, Li H, Liu C. Graphene Oxide-Fullerene C (GO-C) Hybrid for Photodynamic and Photothermal Therapy Triggered by Near-Infrared Light. Biosens bioelectron (2017) 89:477-82. doi: 10.1016/j.bios.2016.03.072

137. Costa-Almeida R, Bogas D, Fernandes J, Timochenco L, Silva F, Meneses J, et al. Near-Infrared Radiation-Based Mild Photohyperthermia Therapy of Non-Melanoma Skin Cancer With PEGylated Reduced Nanographene Oxide. Polymers (2020) 12(8):1840. doi: 10.3390/polym12081840

138. Cheon Y, Bae J, Chung B. Reduced Graphene Oxide Nanosheet for ChemoPhotothermal Therapy. Langmuir ACS J Surfaces Colloids (2016) 32 (11):2731-6. doi: 10.1021/acs.langmuir.6b00315

139. Kargar S, Khoei S, Khoee S, Shirvalilou S, Mahdavi S. Evaluation of the Combined Effect of NIR Laser and Ionizing Radiation on Cellular Damages Induced by IUdR-Loaded PLGA-Coated Nano-Graphene Oxide. Photodiagn Photodyn Ther (2018) 21:91-7. doi: 10.1016/j.pdpdt.2017.11.007

140. Li Z, Li C, Zheng M, Pan J, Zhang L, Deng Y. Functionalized Nano-Graphene Oxide Particles for Targeted Fluorescence Imaging and Photothermy of Glioma U251 Cells. Int J Clin Exp Med (2015) 8(2):1844-52.

141. Dong $\mathrm{H}$, Jin $\mathrm{M}$, Liu Z, Xiong $\mathrm{H}$, Qiu X, Zhang W, et al. In Vitro and In Vivo Brain-Targeting Chemo-Photothermal Therapy Using Graphene Oxide Conjugated With Transferrin for Gliomas. Lasers Med Sci (2016) 31 (6):1123-31. doi: 10.1007/s10103-016-1955-2

142. Akhavan O, Ghaderi E. Graphene Nanomesh Promises Extremely Efficient In Vivo Photothermal Therapy. Small (Weinheim an der Bergstrasse Germany) (2013) 9(21):3593-601. doi: 10.1002/smll.201203106

143. Robinson J, Tabakman S, Liang Y, Wang H, Casalongue H, Vinh D, et al. Ultrasmall Reduced Graphene Oxide With High Near-Infrared Absorbance for Photothermal Therapy. J Am Chem Soc (2011) 133(17):6825-31. doi: $10.1021 / \mathrm{ja} 2010175$

144. Godugu K, Rajabi M, Mousa S. Anti-Cancer Activities of Thyrointegrin $\alpha \beta$ Antagonist Mono- and Bis-Triazole Tetraiodothyroacetic Acid Conjugated via Polyethylene Glycols in Glioblastoma. Cancers (2021) 13(11):2780. doi: $10.3390 /$ cancers 13112780

145. Huang L, Lin H, Chen Q, Yu L, Bai D. MPPa-PDT Suppresses Breast Tumor Migration/Invasion by Inhibiting Akt-NF-Kb-Dependent MMP-9 Expression via ROS. BMC Cancer (2019) 19(1):1159. doi: 10.1186/s12885019-6374-x

146. Wei Y, Zhou F, Zhang D, Chen Q, Xing D. A Graphene Oxide Based Smart Drug Delivery System for Tumor Mitochondria-Targeting Photodynamic Therapy. Nanoscale (2016) 8(6):3530-8. doi: 10.1039/C5NR07785K

147. Makharza SA, Cirillo G, Vittorio O, Valli E, Voli F, Farfalla A, et al. Magnetic Graphene Oxide Nanocarrier for Targeted Delivery of Cisplatin: A Perspective for Glioblastoma Treatment. Pharmaceuticals (Basel) (2019) 12 (2):76. doi: $10.3390 / \mathrm{ph} 12020076$

148. Yang HW, Huang CY, Lin CW, Liu HL, Huang CW, Liao SS, et al. Gadolinium-Functionalized Nanographene Oxide for Combined Drug and microRNA Delivery and Magnetic Resonance Imaging. Biomaterials (2014) 35(24):6534-42. doi: 10.1016/j.biomaterials.2014.04.057

149. Su S, Wang J, Vargas E, Wei J, Martínez-Zaguilán R, Sennoune SR, et al. Porphyrin Immobilized Nanographene Oxide for Enhanced and Targeted Photothermal Therapy of Brain Cancer. ACS Biomater Sci Eng (2016) 2 (8):1357-66. doi: 10.1021/acsbiomaterials.6b00290

150. Song J, Yang X, Jacobson O, Lin L, Huang P, Niu G, et al. Sequential Drug Release and Enhanced Photothermal and Photoacoustic Effect of Hybrid Reduced Graphene Oxide-Loaded Ultrasmall Gold Nanorod Vesicles for Cancer Therapy. ACS Nano (2015) 9(9):9199-209. doi: 10.1021/ acsnano. 5 b03804

151. de Melo-Diogo D, Lima-Sousa R, Alves C, Costa E, Louro R, Correia I. Functionalization of Graphene Family Nanomaterials for Application in Cancer Therapy. Colloids Surfaces B Biointerfaces (2018) 171:260-75. doi: 10.1016/j.colsurfb.2018.07.030

152. Rahmanian N, Eskandani M, Barar J, Omidi Y. Recent Trends in Targeted Therapy of Cancer Using Graphene Oxide-Modified Multifunctional Nanomedicines. J Drug Target (2017) 25(3):202-15. doi: 10.1080/ 1061186X.2016.1238475

153. Zhu X, Zhang Y, Huang H, Zhang H, Hou L, Zhang Z. Functionalized Graphene Oxide-Based Thermosensitive Hydrogel for Near-Infrared Chemo-Photothermal Therapy on Tumor. J Biomater Appl (2016) 30 (8):1230-41. doi: $10.1177 / 0885328215619583$ 
154. Pei X, Zhu Z, Gan Z, Chen J, Zhang X, Cheng X, et al. PEGylated NanoGraphene Oxide as a Nanocarrier for Delivering Mixed Anticancer Drugs to Improve Anticancer Activity. Sci Rep (2020) 10(1):2717. doi: 10.1038/ s41598-020-59624-w

155. Islami M, Zarrabi A, Tada S, Kawamoto M, Isoshima T, Ito Y. Controlled Quercetin Release From High-Capacity-Loading Hyperbranched Polyglycerol-Functionalized Graphene Oxide. Int J Nanomed (2018) 13:6059-71. doi: 10.2147/IJN.S178374

156. Chong Y, Ma Y, Shen $\mathrm{H}, \mathrm{Tu} \mathrm{X}$, Zhou X, Xu J, et al. The In Vitro and In Vivo Toxicity of Graphene Quantum Dots. Biomaterials (2014) 35(19):5041-8. doi: 10.1016/j.biomaterials.2014.03.021

157. Shahriari S, Sastry M, Panjikar S, Singh Raman RK. Graphene and Graphene Oxide as a Support for Biomolecules in the Development of Biosensors. Nanotechnol Sci Appl (2021) 14:197-220. doi: 10.2147/ NSA.S334487

158. Gupta N, Rai D, Jangid A, Kulhari H. A Review of Theranostics Applications and Toxicities of Carbon Nanomaterials. Curr Drug Metab (2019) 20 (6):506-32. doi: 10.2174/1389200219666180925094515

159. Panwar N, Soehartono A, Chan K, Zeng S, Xu G, Qu J, et al. Nanocarbons for Biology and Medicine: Sensing, Imaging, and Drug Delivery. Chem Rev (2019) 119(16):9559-656. doi: 10.1021/acs.chemrev.9b00099

160. Bao H, Pan Y, Ping Y, Sahoo N, Wu T, Li L, et al. Chitosan-Functionalized Graphene Oxide as a Nanocarrier for Drug and Gene Delivery. Small
(Weinheim an der Bergstrasse Germany) (2011) 7(11):1569-78. doi: 10.1002/smll.201100191

161. Mousavi S, Hashemi S, Ghasemi Y, Amani A, Babapoor A, Arjmand O. Applications of Graphene Oxide in Case of Nanomedicines and Nanocarriers for Biomolecules: Review Study. Drug Metab Rev (2019) 51 (1):12-41. doi: 10.1080/03602532.2018.1522328

Conflict of Interest: The authors declare that the research was conducted in the absence of any commercial or financial relationships that could be construed as a potential conflict of interest.

Publisher's Note: All claims expressed in this article are solely those of the authors and do not necessarily represent those of their affiliated organizations, or those of the publisher, the editors and the reviewers. Any product that may be evaluated in this article, or claim that may be made by its manufacturer, is not guaranteed or endorsed by the publisher.

Copyright (c) 2022 Wang, Guo, Xu, Chen, Zhao and Yu. This is an open-access article distributed under the terms of the Creative Commons Attribution License (CC BY). The use, distribution or reproduction in other forums is permitted, provided the original author(s) and the copyright owner(s) are credited and that the original publication in this journal is cited, in accordance with accepted academic practice. No use, distribution or reproduction is permitted which does not comply with these terms. 